\title{
The List of Competences of Clinical Psychologists as a Professional Asset
}

\author{
Martin grosse Holtforth ${ }^{\mathrm{a}}$
}

[a] University of Bern \& Inselspital Bern, Bern, Switzerland.

Clinical Psychology in Europe, 2019, Vol. 1(2), Article e37420, https://doi.org/10.32872/cpe.v1i2.37420

Published (VoR): 2019-06-28

Corresponding Author: Martin grosse Holtforth, University of Bern, Clinical Psychology and Psychotherapy, Fabrikstr. 8, CH-3012 Bern and Psychosomatic Competence Center, Inselspital, Haus C.L.Lory, U1 59, CH-3010 Bern. E-mail: martin.grosse@psy.unibe.ch

The EACLIPT task force on "Competences of Clinical Psychologists" (this issue; EACLIPT, 2019) has proposed a list of core competences of European clinical psychologists. The document is a discussion paper that outlines a competence profile that covers both, professional knowledge as well as clinical skills. The list of criteria is not considered final, is open to discussion, and shall be updated regularly in interaction with changing environments, new scientific evidence as well as national and/or cultural specificities.

The list extends existing lists of competences (e.g., by the University College of London, n.d.) by not only defining the competences of psychotherapists as a major subgroup of clinical psychologists, but also listing e.g. diagnostic and methodological competences. Thereby, the list covers a wider and more comprehensive range of knowledge and skills of clinical psychologists. Importantly, the task force refrained from defining competences of clinical psychologists in reference to overarching theoretical models or schools. By that, clinical psychologists' competences as well as the quality of their services are defined and may be evaluated regardless of potentially underlying theoretical orientation.

With the presented list, the task force provides an important service to patients and families, to the profession of clinical psychologists as a whole, to society, to educational institutions and students/trainees, as well as to research.

For patients and their families, the list of competencies transparently defines what patients can expect to receive from professionals justifiably calling themselves "clinical psychologist." Thereby, the list may assist potential "customers" and/or patients to navigate through the "psycho-jungle" in search of help for psychological problems and may enable patients to better distinguish between good and not-so-good services. Relatedly, the list 
may also help pinpointing potential malpractice by incompetent, wrong, or fraudulent practice of clinical psychologists.

For clinical psychologists as a profession, the list may help to define themselves as a psychology profession, to support the development of a professional identity, as well as to unite clinical psychologists as a group in political and/or professional struggles within respective health care systems. The list may also facilitate communication and cooperation with health care providers of other professions as well as their societies. Depending on the respective national health care system, the list of competences may also help clinical psychologists to receive reimbursement by health insurances. An internationally agreed-upon list of competences of clinical psychologists will foster clinicians' mobility across Europe by defining standard criteria of clinical psychologists' expertise and thereby facilitate accreditation of professional titles by foreign health care systems. A European definition of competences will also facilitate international professional exchange and collaboration within Europe and beyond.

As Strauß and Kohl (2009) have shown for the subgroup of psychotherapists, the conditions of training and practice of clinical psychologists in Europe greatly vary depending on the respective national health care system and can be expected to vary even more if not only psychotherapists are considered. Having an agreed-upon list of competences of clinical psychologists in Europe will surely make professional life easier for practising clinical psychologists as well as health administrators. In case the title of "clinical psychologist" is not yet legally protected and regulated in a particular European country, the list of competences will help to develop legislation related to mental health services in general and clinical psychology in specific. As part of this, the list may also help to develop and refine quality criteria as well as ethical standards and thereby strengthen the trust in clinical psychologists as a profession.

For educational institutions offering teaching and training of future clinical psychologists, the list of competences helps to specify the knowledge and skills that students and trainees should attain to receive an academic degree and/or professional title. However, the question which knowledge and which skills should be taught/trained at which level (Bachelor, master, postgraduate training) and by which institution(s) will have to be answered by specialists within a respective national educational and health care system in coordination with respective authorities.

Future development of potential hierarchies of competences to be sequentially attained may help to develop curricula at different levels of expertise and thereby potentially "streamline" teaching and training in clinical psychology. An according optimization by levels of training may reduce the time and money spent by clinical psychologists in training as well as by the society. Furthermore, the list of competences may not only help to structure curricula, but in turn, practical experiences with implementing the criteria within curricula will inform the continuous refinement, extension and revision of the criteria and the curricula. 
Research may also profit from the explication of competence criteria by the EACLIPT list. For example, the teaching and training of single skills, such as interpersonal skills, may be evaluated and may lead to scientifically founded recommendations for eventual modifications of training contents and/or procedures. Also, the explication of clinical skills will facilitate research including diverse therapists and will help to identify potential moderators of skill acquisition. Identification of moderators of skill acquisition may aid the individualization of trainings. Furthermore, the explication of clinical skills nicely parallels the systematic differentiation and research of moderators, mechanisms, and processes of change in psychotherapy (Crits-Christoph, Connolly Gibbons, \& Mukherjee, 2013; Doss, 2004), which may to be applied for examining the wider range of clinical psychology and may be brought together to advance our theoretical and clinical knowledge.

Like the list of competences itself, the list of beneficiaries and benefits of the EACLIPT list of competences has to be incomplete and can be extended.

Overall, clinical psychologists having acquired competences as defined by the EACLIPT list will have an excellent foundation for their professional practice of clinical psychology in service of fostering the best possible mental health of their patients.

\section{References}

Crits-Christoph, P., Connolly Gibbons, M. B., \& Mukherjee, D. (2013). Psychotherapy processoutcome research. In M. J. Lambert (Ed.), Bergin and Garfield's handbook of psychotherapy and behavior change (6th ed., pp. 298-340). New York, NY, USA: Wiley.

Doss, B. D. (2004). Changing the way we study change in psychotherapy. Clinical Psychology: Science and Practice, 11(4), 368-386. https://doi.org/10.1093/clipsy.bph094

EACLIPT Task Force On "Competences of Clinical Psychologists". (2019). Competences of clinical psychologists. Clinical Psychology in Europe, 1(2), Article e35551. https://doi.org/10.32872/cpe.v1i2.35551

Strauß, B., \& Kohl, S. (2009). Entwicklung der Psychotherapie und der Psychotherapieausbildung in europäischen Ländern [Development of psychotherapy and psychotherapy training in European countries]. Psychotherapeut, 54(6), 457-463. https://doi.org/10.1007/s00278-009-0703-5

University College of London. (n.d.). Competence frameworks. Retrieved from https://www.ucl.ac.uk/pals/research/clinical-educational-and-health-psychology/researchgroups/core/competence-frameworks 


\section{EACLIPT}

Clinical Psychology in Europe (CPE) is the official journal of the European Association of Clinical Psychology and Psychological Treatment (EACLIPT).

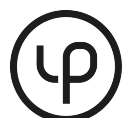

leibniz-psychology.org

PsychOpen GOLD is a publishing service by Leibniz Institute for Psychology Information (ZPID), Germany. 